\title{
CHARGE, MEMÓRIA E POLÊMICA: o caso Bolsonaro
}

\author{
POLITICAL CARTOON, MEMORY, \\ CONTROVERSY: the Bolsonaro case
}

\begin{abstract}
CARMELINO, Ana Cristina
Doutora em Linguística e Língua Portuguesa pela Universidade Estadual Paulista "Júlio de Mesquita Filho" (UNESP/CAr).

Docente do Departamento de Letras da Universidade Federal de São Paulo (UNIFESP).

E-mail: anacriscarmelino@gmail.com

ORCID: https://orcid.org/0000-0002-7576-0595
\end{abstract}

POSSENTI, Sírio

Doutor em Linguística pela Universidade Estadual de Campinas (UNICAMP).

Professor titular do Departamento de Linguística da Universidade Estadual de Campinas

(UNICAMP). Bolsista Produtividade A1 do Conselho Nacional de Desenvolvimento Científico e

Tecnológico (CNPq).

E-mail: siriop@terra.com.br

ORCID: https://orcid.org/0000-0002-3358-4984

\section{RESUMO:}

Este artigo se divide em três partes. Em primeiro lugar, faz uma breve exposição sobre memória, ethos e polêmica, conceitos-chave da Análise do Discurso que auxiliam na leitura de charges. Em segundo lugar, apresenta uma caracterização da charge como um gênero humorístico, com ênfase em elementos que facilitam ou dificultam sua interpretação, conforme sua ligação com um contexto mais ou menos imediato e conforme as informações que ela demanda por parte do leitor. Por fim, analisa algumas charges em função do ethos que as personagens retratadas dão a perceber.

Palavras-chave: charge; humor; polêmica; política; Bolsonaro.

\section{ABSTRACT:}

This article is divided in three parts. Firstly, it gives a brief exposition about memory, ethos and controversy, key concepts of Discourse Analysis that assist the reading of cartoons. Secondly, it presents a characterization of the political cartoon as a humorous genre, 
with emphasis on elements that facilitate or hinder its interpretation, according to its connection with a more immediate or less context and according to the information that the political cartoon demands from the reader. Finally, it analyzes some political cartoons according the ethos that the portrayed characters show.

Keywords: political cartoon; humor; controversy; politics; Bolsonaro.

\section{CONSIDERAÇÕES INICIAIS}

Figura 1 - Renato Aroeira, Humor político, 8 jul. 2018.



Fonte: Disponível em: <https://www.humorpolitico.com.br/aroeira/bolsonaro-ou-o-desejo-masoquista/> Legenda: "No flagrante, o deputado defende seus princípios, seus meios e seus fins"

A charge mostrada acima foi produzida em 8 de julho de 2018 por Renato Aroeira, um conhecido cartunista brasileiro que trabalha no jornal O Dia (do Rio de Janeiro) e enfatiza em suas produções gráficas eventos e personagens políticos. Construída em único momento, traz à cena a imagem de Jair Bolsonaro - na época, deputado federal e candidato às eleições presidenciais no Brasil - trajado de terno e gravata, com duas patas de cavalo com ferraduras no lugar dos dedos das mãos, impulsionado para frente, em posição de ataque.

No caso, o chargista busca colocar em evidência (um pouco hiperbolicamente, reconheça-se) a grosseria de Bolsonaro. A 
legenda remete a um episódio em que ele disse que não estupraria uma determinada deputada porque ela não o merecia ${ }^{1}$. A afirmação foi seguida de discussão áspera, tanto pelo tom quanto pelo comportamento. Na charge, tal leitura pode ser depreendida pelo enunciado verbal (legenda) e pelo não-verbal (Bolsonaro identificado à imagem de um cavalo atacando).

O humor decorre do fato de Bolsonaro ser igualado a um cavalo em posição de ataque. Em português, uma das acepções de "cavalo" é violento. No caso, o chargista constrói para Bolsonaro o ethos (ou o apresenta como) de grosseiro, estúpido, violento. Duas figuras funcionam, portanto, como técnicas para a construção da comicidade dessa produção gráfica: a metonímia, uma vez que é possível remeter à imagem do "cavalo" apenas a partir das "patas com ferradura", e a hipérbole, que pode ser vista no exagero ao se recriar o acontecimento de forma ficcional.

As charges, conforme registram Possenti e Carmelino (2016), são produções humorísticas que tendem a questionar, criticar, denunciar (talvez mais do que divertir), e que remetem tipicamente a pessoas conhecidas e a acontecimentos próximos de sua publicação, como na Figura 1. A última eleição à presidência do Brasil, ocorrida em outubro de 2018, tornou-se um acontecimento marcado por uma série de discursos polêmicos. Parte deles envolveu o candidato eleito, Jair Messias Bolsonaro.

Militar da reserva e político brasileiro, foi deputado federal de 1991 a 2018, completando sete mandatos. O seu plano de governo (filiado ao Partido Social Liberal - PSL) - que teve como lema "Brasil acima de tudo. Deus acima de todos" e título "O Caminho da Prosperidade" - propunha uma gestão "decente, diferente de tudo aquilo que nos jogou em uma crise ética, moral e fiscal. Um governo sem toma lá-dá-cá, sem acordos espúrios" (BOLSONARO, 2018).

$\mathrm{Na}$ verdade, tanto a proposta de governo quanto os discursos inflamados de Bolsonaro durante a campanha e antes mesmo de se candidatar, considerados por muitos como preconceituosos e autoritários, explicam, de certa forma, sua polêmica candidatura. Seus discursos ensejaram um grande número de charges, oferecendo

1 O vídeo que mostra a discussão travada entre Bolsonaro e a deputada federal pelo Rio Grande do Sul, Maria do Rosário Nunes, filiada ao Partido dos Trabalhadores que reflete a cena a que se refere a charge está disponível em: <https://www.youtube.com/watch?v=yRV98Im5zRs>. Acesso em: 5 dez. 2019. 
interpretações humorísticas com forte teor crítico. Magalhães (2019), a título de informação, contextualiza bem a situação vivida no país à época.

Durante seus mandatos como deputado federal, não se soube de projetos de lei que o tornassem conhecido da sociedade brasileira. Sua notoriedade decorreu de seus pronunciamentos bastante radicais, alguns deles parecendo à época folclóricos. Defensor da ditadura militar, inimigo das políticas dirigidas a negros e indígenas, crítico de medidas que indenizaram perseguidos políticos do tempo da ditadura, tornou-se popular especialmente a partir da abertura do processo de impeachment de Dilma Rousseff. Em seu voto, homenageou o Coronel Brilhante Ustra ${ }^{2}$, que chamou de "o terror a Dilma", abonando as notícias de que ele a teria torturado na prisão.

Seus pronunciamentos contra as reservas para indígenas e quilombolas (aos quais se referiu em termos tipicamente aplicados a animais, falando de seu peso em arrobas) e suas referências sempre derrisórias às mulheres e aos homossexuais se tornaram conhecidos e foram frequentemente questionados. Sempre que teve oportunidade de retomá-los, ele os reforçou. Também se pronunciou em favor da ação das milícias e de policiais, mesmo quando eram acusados de violência. Tornaram-se conhecidas declarações como "tive uma fraquejada e nasceu uma menina", por exemplo. Recentemente, já presidente, saudou um descendente de japonês em um aeroporto repetindo um clichê sobre o tamanho de seus órgãos genitais: "tudo pequeno aí?" (cf. Jornal Extra, 15 mai. 2019).

Sua política em favor da facilitação da compra de armas também o associa à violência, embora ele a apresente como um direito das pessoas de bem para se defenderem dos "bandidos". Tem feito um governo controverso, profere declarações grosseiras, agressivas e mesmo mal-educadas, pelas quais nunca manifestou arrependimento, mesmo se produzam efeitos diplomáticos negativos. Tem sido considerado frequentemente grosseiro e debochado, embora ele se caracterize (e pessoas próximas repitam a mesma classificação) como "autêntico" e "sincero". Pode-se dizer que estas duas avaliações (grosseiro versus autêntico) estão em relação polêmica. A charge, como gênero humorístico que busca criticar, toma partido pela grosseria, em detrimento da autenticidade.

2 Carlos Alberto Brilhante Ustra foi um coronel do Exército Brasileiro, ex-chefe do DOI-CODI do II Exército, um dos órgãos atuantes na repressão política, durante o período da ditadura militar no Brasil. 
A charge de Carlos Henrique Latuff de Sousa (Figura 2), produzida em 29 de março de 2011 e veiculada na Revista Forum, resume parte das considerações feitas acima sobre Bolsonaro.

Figura 2 - Carlos Henrique Latuff, Revista Forum, 29 mar. 2011.

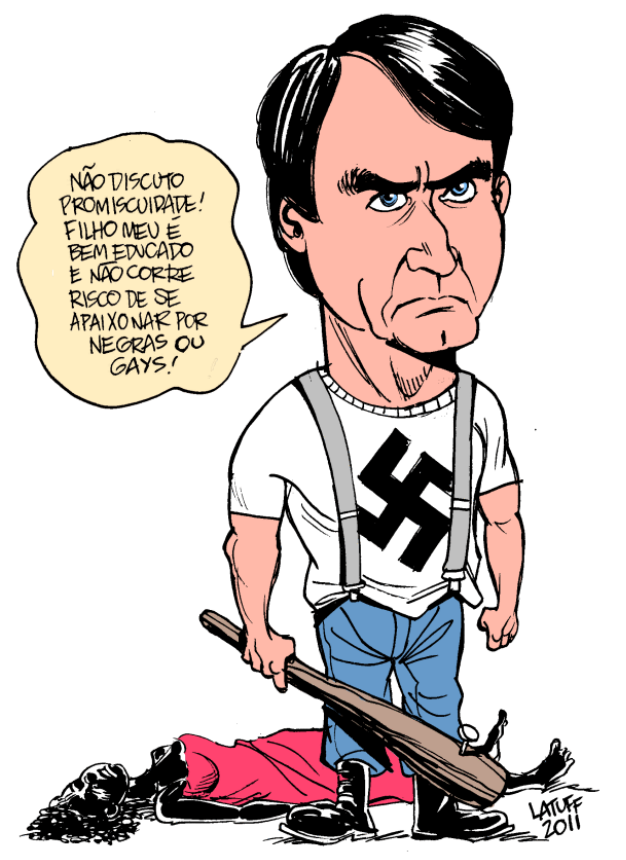

Fonte: Disponível em: https://revistaforum.com.br/blogs/mariafro/bmariafro-bolsonaro-por-latuff/

Legenda: "Não discuto promiscuidade! Filho meu é bem educado e não corre o risco de se apaixonar por negras ou gays!"

Partindo dessas considerações, este artigo pretende analisar charges que circularam na Internet alusivas principalmente a falas e atitudes de Bolsonaro, tanto no período anterior a sua eleição quanto depois, incluindo fatos de seu governo, verificando simultaneamente os discursos veiculados e as técnicas empregadas para produzir efeitos de humor. Os conceitos mobilizados são provenientes de teorias do discurso. O trabalho considerará especialmente as noções de ethos discursivo (MAINGUENEAU, 1984, 1998, 2008a, 2008b), de polêmica (AMOSSY, 2017) e de memória discursiva (COURTINE, 2009; PÊCHEUX, 1999), cruciais para a compreensão das charges. 


\section{HUMOR, MEMÓRIA, POLÊMICA E EthOS}

\section{a) HUMOR E MEMÓRIA}

Aceitando que o humor é um campo ${ }^{3}$ (cf. POSSENTI, 2014), no interior do qual há diversas tendências ou "escolas" e uma multiplicidade de gêneros (da comédia ao meme), certamente se pode assumir que a charge é um gênero, seja por sua estrutura, seja por suas formas de circulação e também por sua peculiar relação com o contexto histórico e social. É tipicamente composta de uma só figura e é geralmente relativa a algum evento próximo. Pode-se mesmo dizer que é um gênero opinativo. A Folha de S.Paulo, por exemplo, publica uma charge diariamente na página 2 , que é a página dos editoriais e das colunas de opinião, criticando, denunciando, muito mais do que propriamente divertindo (cf. POSSENTI; CARMELINO, 2016). Trata-se de um gênero opinativo, multimodal e assinado, que resume situações ou fatos que a sociedade, ou parte dela, conhece. Versa sobre temas e pessoas reais, que são recriados ficcionalmente com recursos gráficos que lhes são próprios - traço que se concretiza em geral pela simplificação, por um lado, e pelo exagero, por outro ${ }^{4}$. Assim, tendem a retomar e a transmitir ou comentar múltiplas informações, estabelecendo um jogo sutil entre o interdito e o permitido (cf. TEIXEIRA, 2005).

Embora as charges tenham se propagado e se consolidado nos jornais impressos, verifica-se uma peculiar expansão delas neste século: além de jornais virtuais, passaram a ser veiculadas em sites exclusivos (caso do <www.chargeonline.com.br $>$ ) e blogs de chargistas, entre outros. Esse dado é relevante para este texto, visto que as charges selecionadas para análise circularam em diferentes ambientes.

A interpretação das charges requer recuperar os enunciados e/ ou os fatos, comumente veiculados pela imprensa, que motivaram sua criação. Sem essas informações, torna-se difícil saber qual seu tema e mesmo compreender como o riso é suscitado. Se o leitor das charges não dispuser de informações sobre pessoas ou fatos a que elas aludem (informações que circulam na sociedade), ou seja, se não tiver uma memória de tais informações, não terá condições de descobrir

3 O conceito de campo, proposto por Bourdieu (2004) e reformulado por Maingueneau (2005), é caracterizado no interior de um universo discursivo, no qual é possível isolar espaços discursivos que mantêm relação com certos discursos.

4 Estes dois traços fazem com que a charge se aproxime às vezes da caricatura. 
seu sentido pretendido. Por isso, ela é especialmente relevante nesse gênero humorístico.

Segundo Pêcheux (1999, p. 11), o conceito de memória se refere a um implícito, a algo coletivo, a uma maneira de estruturar o discurso que "vai constituir a materialidade de uma certa memória social". Assim, para a Análise do Discurso, a memória não é apenas uma lembrança, mas é coletiva, já que reflete elementos anteriores e exteriores a um enunciado ${ }^{5}$. Courtine (2009) diz que há dois movimentos no tocante à relação entre discursividade e memória: o primeiro é uma retomada de discursos, mesmo que transformados; o segundo, de esquecimento, de apagamento.

Para as análises das charges, interessam principalmente as retomadas, visto que elas recuperam formulações enunciadas anteriormente. Citando de novo as palavras de Courtine (2009, p. 104), "toda formulação apresenta em seu 'domínio associado' outras formulações que ela repete, refuta, transforma, denega, isto é, em relação às quais ela produz efeitos de memória específicos".

b) POLÊMICA

É quase um consenso que a sociedade brasileira está dividida e que os "debates" (se puderem assim ser chamados) têm sido radicais e até grosseiros, especialmente nas mídias sociais. Tem havido alguns debates em programas de TV e em artigos de jornais e revistas (e até mesmo apelos para que eles ocorram), mas há muito mais casos de disputas ou mesmo de bate-bocas ${ }^{6}$.

A polêmica, segundo Amossy (2017, p. 49), "é um debate em torno de uma questão de atualidade, de interesse público, que comporta os anseios da sociedade mais ou menos importantes numa dada cultura". Uma de suas marcas é a oposição de discursos, não mera disputa ou discordância entre pessoas. Assim, o antagonismo das posições em um confronto verbal é sua condição sine qua non. Segundo a autora, a noção de confrontação designa a ação de colocar pelo menos dois discursos em relação, permitindo assim uma apreciação por comparação.

5 O conceito de memória tem a finalidade de explicitar que não se fala a partir de nada, mas retomando discursos já ocorridos. É um dos exemplos de pré-discurso, um conceito exposto por de Paveau (2006).

6 Para as diferenças entre debates, controvérsias, polêmicas e disputas, ver M. Dascal, "Epistemologia, controvérsias e pragmática", publicado na Revista do SBHC, 12, p. 73-98, 1994, Disponível em: <https://docs.ufpr.br/ borges/ publicacoes/notaveis/dascal94.pdf> [textos notáveis] 
Amossy (2017) destaca alguns traços que, numa dada situação, dão à polêmica sua especificidade. Tais traços são a dicotomização, a polarização e a desqualificação do outro. Em linhas gerais, conforme a autora, a dicotomização, de ordem conceitual, exacerba as oposições (como direita/esquerda, tolerante/intolerante, justiça/injustiça, etc.), tornando-as inconciliáveis; as opiniões antagônicas se excluem mutuamente. A polarização, de ordem social, consiste em estabelecer campos adversários entre participantes oriundos de categorias diversas que se constituem por identificação; uma variedade de vozes se faz ouvir. Por fim, a desqualificação do outro ocorre quando um grupo deprecia, ataca, rebaixa o "oponente"; tal traço, segundo Amossy (2017), singulariza a polêmica verbal.

Algumas características da polêmica registradas pela autora estão relacionadas à circulação e estruturação dos enunciados, bem como à sua duração na mídia. Para Amossy, é na circulação de discursos no espaço público que a polêmica se constrói como um debate verbal sobre uma questão social. Quanto à duração das polêmicas, Amossy (2017, p. 48) diz que em geral são efêmeras: "estreitamente ligada àquilo que preocupa o público num momento preciso, e muitas vezes é tão rapidamente esquecida quanto inflamada na hora em que eclode". A pesquisadora destaca ainda que: i) os sentidos e os anseios da polêmica deixam de ser perceptíveis para além de sua duração; e i) alguns deduzem que o estudo das polêmicas se reduz ao estudo de textos fugazes e rapidamente desatualizados.

Uma concepção peculiar de polêmica é proposta por Maingueneau (1984), para quem ela ocorre entre duas formações discursivas que tentam ocupar o mesmo espaço ideológico. Segundo o autor, esse tipo de polêmica se caracteriza pelo fato de que uma posição ( $A$, digamos) interpreta a outra $(B$, digamos) a partir de seus próprios pontos de vista. O efeito é um simulacro do discurso do outro, o que faz com que a polêmica nunca se resolva. Um exemplo de simulacro é a leitura de "bolsa família" como "bolsa esmola", ou de "ocupação" como "invasão" e vice-versa.

No caso do corpus que estamos analisando, as polêmicas são mais parecidas com as descritas por Amossy (2017) do que com as descritas por Maingueneau (1984). No entanto, pode-se propor a hipótese de que uma representação chárgica seja um simulacro (por exemplo, representar um conservador como nazista). 


\section{c) $E T H O S$}

Pode-se creditar a Dominique Maingueneau a vinculação do conceito de ethos aos estudos discursivos. O termo, advindo da Grécia antiga, especificamente da Retórica, vem sendo apropriado e reinterpretado desde então em variadas perspectivas teóricas. Para Maingueneau, por exemplo, qualquer discurso, seja escrito ou oral, "implica certa representação do corpo de seu responsável, do enunciador que se responsabiliza por ele" (MAINGUENEAU, 1998, p. $60)$, vale dizer, seu ethos.

Seguindo esta tese, identifica-se o ethos por meio de registros linguísticos manifestados (ou materializados) nos textos, em uma situação concreta de enunciação por intermédio de um sujeito enunciador, que se torna responsável pelo que profere (nos termos do pesquisador, configura-se como fiador do enunciado). O discurso deste sujeito é proferido em certo tom, que implica uma corporalidade e um caráter, traços físicos e psicológicos, respectivamente, que são atribuídos ao enunciador pelo leitor / ouvinte a partir de representações, muitas vezes, estereotipadas (cf. MAINGUENEAU, 2008b).

O ethos é um efeito da enunciação. Pode estar associado a uma formação discursiva (como a "doçura" do humanismo devoto), a escolas (como nos poemas condoreiros) ou um campo (a "objetividade" da ciência). Eventualmente, o ethos faz parte da caracterização de personagens literárias (como Quixote e Sancho). Comumente decorre da enunciação, mas, se o enunciador é uma personagem conhecida do público (um político, um artista, um intelectual militante), pode haver uma representação prévia, o que constituiria um ethos prévio ou pré-discursivo (MAINGUENEAU, 2008b), confirmado ou não pela enunciação. Além disso, o ethos, tipicamente mostrado, decorrente do tom da enunciação, pode ser explicitado pelo enunciador (não sou xiita, sou sincero), configurando o que o mesmo autor chama de ethos dito.

Maingueneau (2008b) estabelece uma relação entre a imagem do fiador e a de estereótipo. Para ele, o público se ancora em representações sociais cristalizadas, estereotipadas, para associar os comportamentos verbais e não verbais do enunciador a um determinado mundo ético, reforçado ou modificado pela enunciação.

Ainda que os alicerces teóricos sobre ethos tenham se ancorado (em grande parte) no discurso verbal (oral ou escrito) manifestado por 
enunciadores, é possível ampliar o conceito para produções pautadas também na imagem (cf. CARMELINO; RAMOS, 2018), como é o caso das charges. Compostas por elementos visuais (imagem e cor) e verbais, falados ou escritos, tais enunciados permitem construir ethé de Bolsonaro.

\section{AS CHARGES E SUA RELAÇÃO COM O CONTEXTO}

Algumas considerações sobre as cinco charges abaixo 7 permitem uma aproximação dos objetivos do trabalho e já explicitam alguns dos procedimentos de análise. As charges, como já dito, são produções humorísticas que remetem tipicamente a pessoas conhecidas e a acontecimentos próximos de sua publicação. Vejamos o seguinte caso:

Figura 3 - Laerte Coutinho, Folha de S. Paulo, 27 ago. 2019.

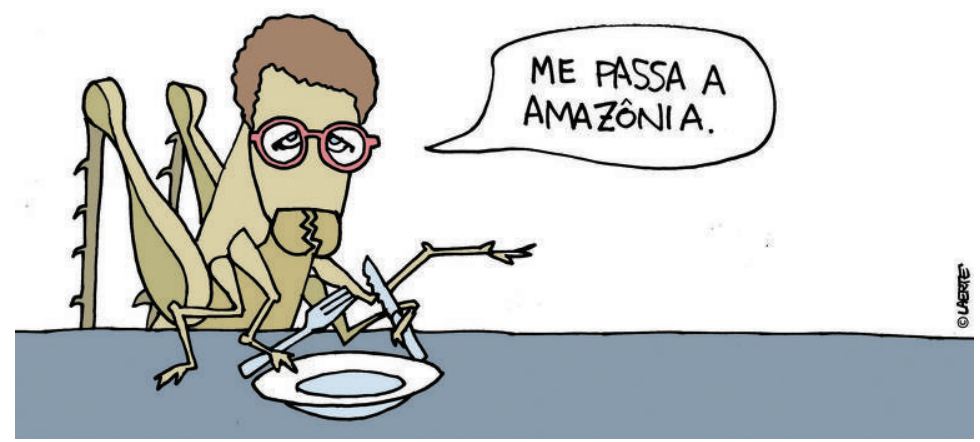

Fonte: Disponível em: <https://fotografia.folha.uol.com.br/galerias/1640632202617954charges-agosto-2019>

Legenda: "Me passe a Amazônia"

No exemplo da Figura 3, o ministro do Meio Ambiente, Ricardo Salles (reconhecível principalmente por seus óculos e por seu cabelo), é representado como um gafanhoto fazendo sua refeição (de forma rebaixada e exagerada, portanto, de onde se extrai o humor), que seria a floresta Amazônia ("Me passa a Amazônia"). O gafanhoto é um inseto conhecido por sua voracidade, que anda em bandos que podem destruir plantações em pouco tempo. A charge reflete uma avaliação segundo a qual ele estaria destruindo a Amazônia, e é publicada em um período marcado por muitas queimadas, o que está relacionado

7 Algumas charges circularam na mídia mais tradicional, e podem ser acessadas a partir do link que as seguem. Mas algumas circularam por aplicativos como o Facebook, e chegaram a nós sem fonte identificável. Pareceunos que incluí-las assim mesmo no corpus era também uma forma de "respeitar" os modos típicos de circulação desses outros canais, que são próprios. 
a uma memória de curto prazo. Circulam discursos controversos sobre o fato: elas decorreriam de um período de seca, muitas delas ocorreriam em propriedades particulares e não seriam ilegais, houve queimadas similares em muitos países etc., dizem alguns. Outros dizem que o aumento do fenômeno neste ano (quer dizer, 2019) se deveria a uma espécie de licença para queimar, decorrente de muitos pronunciamentos e ações oficiais (como a demissão do Presidente do IMPA) que indicariam um afrouxamento das regras até então vigentes, de fiscalização e de punição, até do corte de verbas.

É um exemplo de charge que resume uma polêmica, estreitamente ligada a um período (que se espera que seja breve) e que, portanto, leva em conta uma memória, cuja extensão é a do debate sobre o papel da Amazônia (já antigo), mas que se concentra nos fatos mais recentes. De novo, a charge toma partido por um dos discursos. $\mathrm{O}$ humor crítico, como se nota, decorre do fato de o ministro do Meio Ambiente ser representado, metonímica e hiperbolicamente, como um gafanhoto comendo, uma forma de rebaixá-lo. Vejamos outro caso.

Figura 4 - Bruno Maron, Folha de S.Paulo, 5 ago. 2019.

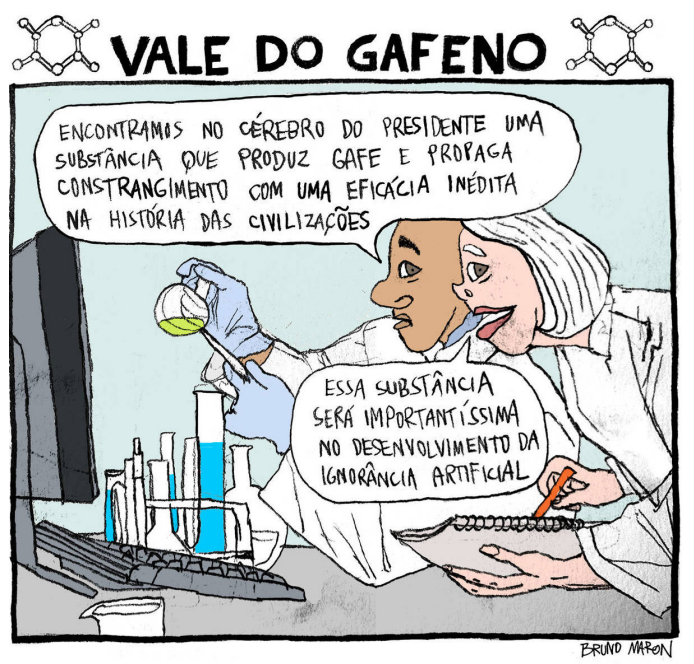

Fonte: Disponível em: <https://www1.folha.uol.com.br/ilustrissima/2018/03/veja-os-cartuns-publicados-pelailustrissima-em-2018.shtml>

Legenda: "VALE DO GAFENO"// "Encontramos no cérebro do presidente uma substância que produz gafe e propaga constrangimento com uma eficácia inédita na história das civilizações" // "Essa substância será importantíssima no desenvolvimento da ignorância artificial". 
A charge da Figura 4 ilustra ou representa casos em que as produções deste gênero retomam eventos não necessariamente particulares e pontuais, como é o caso da primeira e da terceira charges analisadas anteriormente (Figura 1 e Figura 3). O exemplo em questão "diz" que uma substância encontrada no cérebro do presidente faz com que cometa gafes. O nome da substância, "gafeno", lembra, por sua desinência, elementos químicos. O humor decorre não só dessa associação, mas da criação de uma substância ficcional: "gafeno". O sintagma "o presidente" tem como efeito de sentido que o referente seja o atual presidente do Brasil, Jair Bolsonaro. Está aí a relevância da consideração da charge como sendo situada em um tempo histórico, retomando uma memória, mesmo de curta duração. Desse modo, os dados verbais conferem ao presidente o ethos de insensato, ignorante.

O que importa nessa charge, de maneira mais relevante, é que não se refere a um fato particular, mas a uma reiteração de fatos ou comportamentos: as gafes cometidas pelo presidente são muitas (serem provocadas por uma substância caracterizaria este comportamento como uma doença), embora nos dias mais próximos ao da publicação da charge tenham ocorrido diversos fatos relativos a seu desentendimento pessoal com o presidente da França, que permitem avaliar mais facilmente estes pronunciamentos como gafes ${ }^{8}$ e mesmo como grosserias. Trata-se, pois, de um exemplo que "retrata" um comportamento constante, mais do que um fato particular. A legenda "VALE DO GAFENO" alude ao Vale do Silício, um lugar de pesquisas avançadas, propício a descobertas.

Sendo as charges uma retomada simplificada de cenas, de fatos e de pessoas, a recuperação ou representação integral dos elementos envolvidos nos fatos reais é impossível em uma imagem, que é um "texto" breve. Além disso, seu sentido é frequentemente vago. A charge da Figura 5 é um exemplo de vagueza de sentido, ao mesmo tempo em que demanda uma memória. Por isso, sua interpretação também requer uma reconstituição dos fatos dos quais ela deriva ou aos quais alude e interpreta. A personagem retratada no primeiro quadro é José Serra, então Ministro de Relações Exteriores do governo Temer. No segundo quadro, alguém joga vinho na sua cara. No terceiro (Serra

8 Poucos dias depois ele também foi muito pouco diplomático referindo-se à ex-presidenta do Chile, como se pode ver, por exemplo, em: <https://www.brasil247.com/midia/imprensa-de-todo-o-mundo-registra-repudio-aagressao-de-bolsonaro-a-bachelet>. Acesso em: 5 dez. 2019. 
está aparentemente conformado, ou, pelo menos, não revoltado), ele diz que "pelo menos este vinho é uruguaio".

Para a charge fazer sentido, devem ser considerados pelo menos dois fatos: a) algum tempo antes, uma senadora jogou vinho na cara de Serra, em uma festa, porque ele fez afirmações pouco abonadoras (considerados certos valores) sobre sua vida privada; b) Serra, representando o Brasil, e com ele representantes dos governos da Argentina e do Paraguai estariam pressionando o Uruguai a adotar a posição de não permitir que a presidência do Mercosul viesse a ser exercida pela Venezuela, como previsto. A reação do Uruguai foi pouco diplomática: denunciou tentativas de "suborno" em troca do voto favorável. O vinho na cara representa esta reação (nenhum vinho foi "realmente" jogado na cara de Serra por diplomatas uruguaios, como o fora pela senadora). O elemento de maior interesse nesta charge é que a reação anterior de uma senadora que se sentiu ofendida é retomada para representar a posição da diplomacia uruguaia, que reagiria bastante grosseiramente à ofensa ou pelo menos a uma atitude pouco louvável do ministro. O exemplo ilustra um fenômeno comum, o da recuperação de uma memória em fragmentos ou mesmo de forma indireta. No humor, como é sabido, o sentido é frequentemente indireto (cf. DASCAL, 1999).

Figura 5 - Alberto Benett, Folha de S. Paulo, 18 ago. 2016.

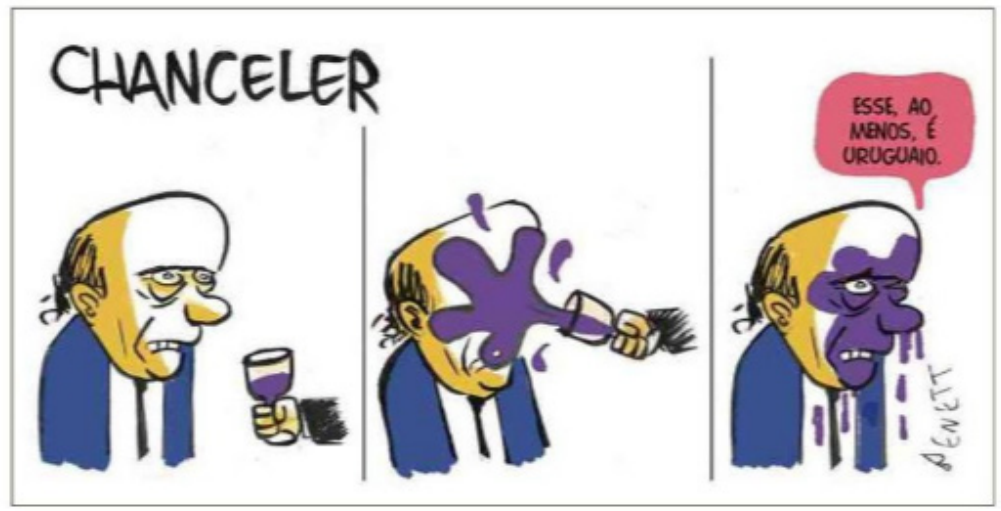

Fonte: Disponível em: <https://acervo.folha.com.br/leitor.do?numero=20686\&anchor=6031762 \&origem=busca\&_ mather=fb7c32c39a3ef652\&pd=8afa9f2e7397f23a726c58ba58bb7d7e>

Legenda: "Chanceler" // "Esse, ao menos, é uruguaio" 
Eventualmente, uma charge pode referir-se a um "clima", a um "ar", obviamente sustentado ou denunciado de diversas maneiras por um discurso, isto é, por um conjunto de textos de diversos gêneros que fazem avaliação de posicionamentos. A charge da Figura 6 (que circulou pelo Facebook) é um exemplo deste caso. Ela se refere, ou materializa, por um lado (na primeira imagem), uma ameaça, a do esmagamento de políticas ou de opiniões "boas", populares, favoráveis à liberdade (representadas pela flor). Remete às ditaduras de forte inspiração militar, aqui representadas pela botina de um soldado esmagando flor. A segunda imagem mostra a flor resistindo, renascendo, furando a botina, representando, portanto, a vitória do "bem" sobre o "mal". Uma associação possível é com os famosos versos de uma canção composta e gravada durante a ditadura ("Pesadelo", de Paulo César Pinheiro), que dizem "você corta um verso / eu escrevo outro / você me prende vivo / eu escapo morto / de repente / olha eu de novo / perturbando a paz / exigindo o troco", exatamente como neste desenho, que significa que a violência será derrotada por ideias que não morrem ${ }^{9}$. Nesta charge está representada uma polêmica. Cada lado se expressa de uma forma: um deles pretende eliminar o adversário; o outro responde que a repressão violenta será vencida no futuro, e de maneira "doce", dados inferidos pelo ethos representado por uma flor que nasce em terreno hostil.

Figura 6 - Charge que circulou no Facebook

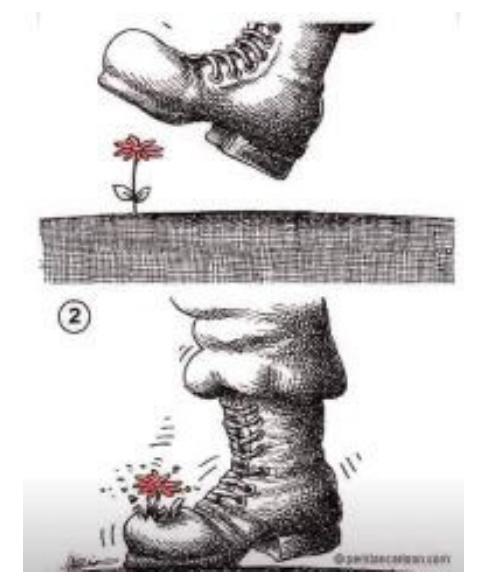

9 Para um depoimento de músicos sobre esta canção e sua execução, pode-se consultar <https://www.youtube. com/watch?v=1Q7ZT3r5dYw>. Acesso em: 5 dez. 2019. 
Uma charge pode contar uma pequena história. É o caso da que se segue (Figura 6), relativa à cerimônia de posse de Bolsonaro, o que é indicado principalmente pelo carro e pela faixa presidencial. A história contada é uma versão de sua eleição, que ganhou espaço nos jornais. Sem mostrar o número de votos e sem mencionar sua validade (Bolsonaro "desconfiava" da urna eletrônica e ameaçou não aceitar um resultado contrário à sua candidatura), o que a charge põe em destaque é o papel das redes sociais na eleição, especialmente do WhatsApp. Tanto que, seguindo uma técnica comum de produção de humor, o exagero, um telefone celular que mostra o símbolo desse aplicativo ocupa o lugar do presidente, inclusive carregando a faixa presidencial. A charge retoma uma memória das posses presidenciais, nas quais têm ocorrido um desfile em carro aberto - uma memória relativamente longa; por outro lado, humoristicamente, retoma-se uma memória de curto prazo, pondo em relevo um celular e o WhatsApp, que remetem ao aspecto da campanha eleitoral, ao papel decisivo das fake news em sua eleição. Retoma-se, assim, também o noticiário polêmico sobre a questão.

Figura 6 - Charge que circulou no Facebook, 1ำ jan. 2019.
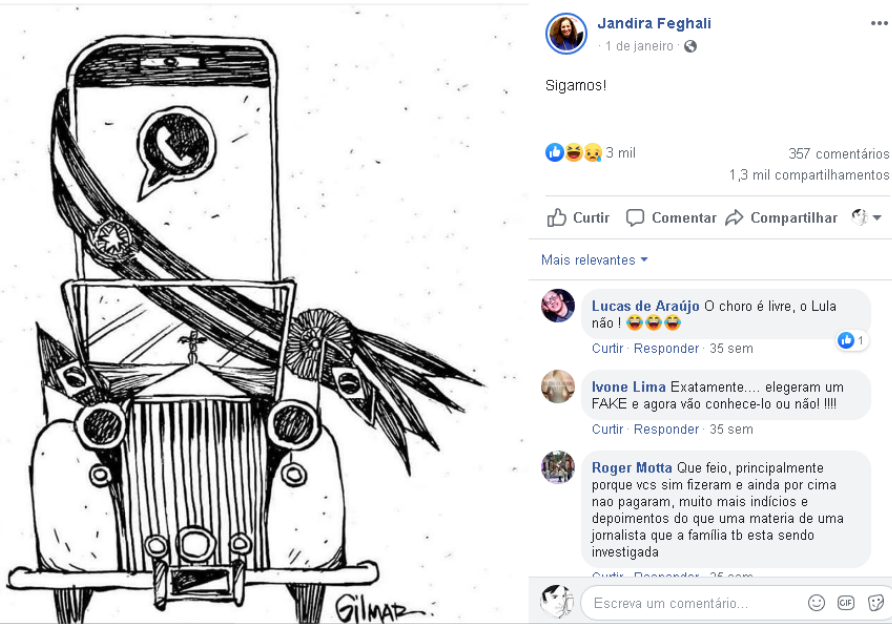

Mais relevantes.

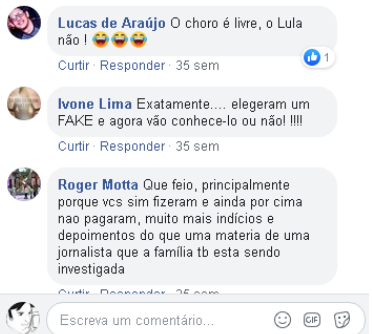

Fonte: Disponível em: https://www.facebook.com/sigajandira2/ 


\section{HUMOR, POLÍTICA E POLÊMICA: EM FOCO OS ETHÉ DE BOLSONARO}

Retomando brevemente as charges mencionadas que remetem a falas e atitudes de Bolsonaro, podemos verificar, resumidamente, alguns ethé construídos para o presidente, quais sejam: grosseiro, estúpido, violento (Figura 1); debochado, preconceituoso (Figura 2) e insensato, ignorante (Figura 4). Além desses, outros dois ethé merecem registro: o de autoritário (a partir de pronunciamentos ameaçadores) e o de antiquado (com base em certos posicionamentos assumidos). Vejamos dois exemplos do primeiro caso.

Figura 7 - Renato Aroeira, O Dia, 31 set. 2018.

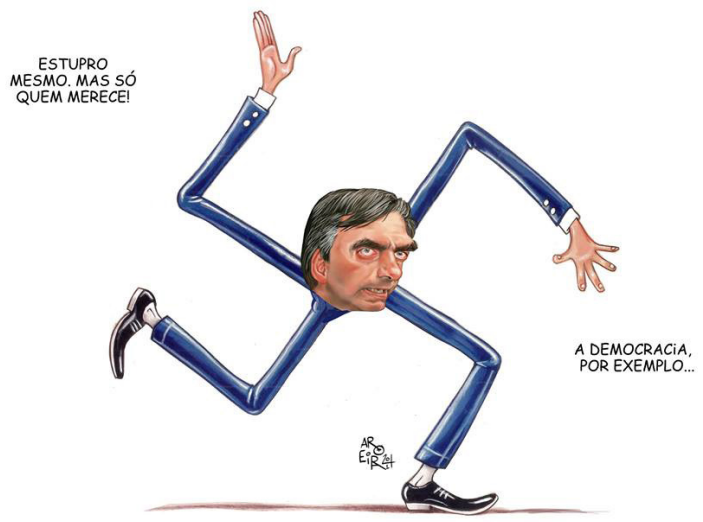

Fonte: Disponível em: <https://www.humorpolitico.com.br/page/2/?s=Bolsonaro+nazista> Legenda: "Estupro mesmo. Mas só quem merece!" // "A Democracia por exemplo..."

Figura 8 - Kamenes, Charge online, 29 out. 2018.

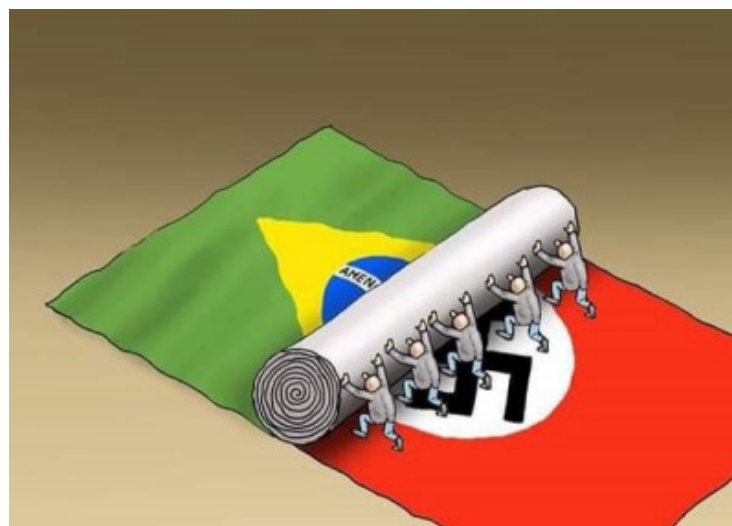

Fonte: Disponível em: <https://www.chargeonline.com.br> 
A charge de Aroeira (Figura 7) capta um discurso corrente entre os adversários de Bolsonaro, segundo o qual ele é fascista / nazista ${ }^{10}$. A produção de humor também se deve à metonímia (o corpo de Bolsonaro é representado pelo símbolo da suástica) e à hipérbole (exagero na representação). Antes dessa charge "eleitoral", circulara outra, também de Aroeira, como a que o retrata como um cavalo, que o representa como se suas pernas e seus braços constituíssem uma suástica. A alusão é clara. A charge de Kamenes, publicada um dia após o presidente ter sido eleito, reforça a leitura de que, a partir daquele momento, implanta-se (retoma-se) outro regime de governo, dado representado pela substituição da bandeira do Brasil por outra, com a símbolo da suástica, que impõe tal leitura. Vale o registro de que no dia de sua eleição circularam (pelo WhatsApp e Facebook) dezenas de charges em que tal classificação era assumida diretamente. Os dois casos retomam a memória de curto prazo, a de que Bolsonaro se apresentou como defensor da ditadura militar, como inimigo das políticas dirigidas a negros e indígenas, crítico de medidas que indenizaram perseguidos políticos do tempo da ditadura, entre outras tomadas de posição consideradas reacionárias e associáveis ao nazismo.

$\mathrm{Na}$ primeira observação de Maingueneau (1984) sobre o que veio a ser desenvolvido pelo autor como ethos, a palavra não aparecia; o que o autor postulava é que todo o texto, mesmo o escrito, tem um tom. Tratava-se obviamente de ethos, como se viu em obras posteriores. Outra questão era central naquela obra: que o ethos é uma característica dos enunciados (e deveria ser também dos enunciadores) produzidos no interior de uma formação discursiva; era um dos traços da semântica global que decorre de um conjunto de semas. Se considerarmos as imagens que mais repetidamente mostram o nazismo, seja nos filmes, seja em documentários, por exemplo, os discursos de Hitler e os soldados marchando no característico passo de ganso, podemos atribuir a esta ideologia, seja pelo tom dos discursos, seja pelo "corpo" dos soldados, um ethos viril, quiçá violento.

Muitos pronunciamentos de Bolsonaro retomam de certa forma aquele tom, como ocorreu no caso de sua agressão à deputada Maria do Rosário, acima comentada (cf. nota de rodapé 1). Em vídeo que

10 A distinção entre nazismo e fascismo é irrelevante para as charges, exceto pelo fado de o símbolo prototípico do nazismo ser mais retomado, por ser mais conhecido 
consta no canal do YouTube ${ }^{11}$, pode-se ouvir o pronunciamento de Bolsonaro, no dia 21 de outubro de 2018, ameaçando adversários de eliminação física, associada à Ponta da Praia, de triste memória, por ser um local em que desapareciam presos políticos durante a ditadura militar.

Pode-se dizer que há uma polêmica a respeito da classificação de Bolsonaro como fascista ou nazista. A acusação é frequente e comum em certos espaços, especialmente nas redes sociais. Mesmo a mídia tradicional inclui esta qualificação, que é também debatida por articulistas provindos da academia. O fato de o tema ter sido suscitado, apesar da ausência de uniformidade de seu tratamento, é um sintoma de que o tema estava na rua. Segue-se pequeníssima amostra dessa polêmica. Por exemplo, Almeida (21 out. 2018) escreve que:

O candidato do PSL não se encaixa na definição do termo, segundo cientistas políticos, filósofos e historiadores. Para os especialistas, no entanto, o discurso do presidenciável pode ser qualificado como de extrema direita, pleno de autoritarismo e com traços semelhantes a aspectos do fascismo.

Um jornal publicou matéria intitulada "Bolsonaro é fascista? Listamos 13 frases do candidato para reflexão" (BIANCHINI, 17 out. 2018). Nela se constata que o candidato de extrema direita Jair Bolsonaro (PSL) tem sido caracterizado como "representante do fascismo" por pesquisadores do tema dentro e fora do país. A matéria acrescente que "o advogado estadunidense Mike Godwin, criador da Lei de Godwin, que critica a banalização das comparações com o nazismo, autorizou pelo Twitter comparações entre Bolsonaro com Hitler".

Para a antropóloga Adriana Dias, que pesquisa sobre neonazismo há 15 anos, o discurso de Bolsonaro é similar ao que Hitler pregava em sua campanha, na Alemanha de 1932. E acrescenta. "A construção do partido nazista foi voltada para a ideia anticorrupção de Estado, muito militarista, fundamentalmente pautada na ideia de que havia

11 Disponível em: <https://www.youtube.com/watch?v=at8qr1MeO6g>. Acesso em: 5 dez. 2019. 
uma Alemanha que estava acabando economicamente", explica Dias (cf. BIANCHINI, 17 out. 2018).

O historiador Federico Finchelstein declara que "Bolsonaro é um dos populistas mais próximos do fascismo que já vi". Autor do ensaio "Do Fascismo ao Populismo na História", mostra sua preocupação com o surgimento de "um novo populismo que combina o neoliberalismo com ranço fascista". Bolsonaro seria um exemplo deste tipo de política (PITA, 4 jul. 2019).

Já Araújo (5 set. 2019) afirma que "a Alemanha nazista, dos primeiros anos da década de 30 do século XX, guardadas as abissais diferenças que nos separam (ênfase minha), tem muito a "ensinar" ao Brasil de hoje sobre a escalada do poder autoritário, do arbítrio, da violência, do ataque aos "inimigos", da conspurcação das instituições, da inércia do povo em face do perigo que o espreita".

A tese de que Bolsonaro é fascista / nazista ${ }^{12}$ foi claramente assumida por muitos brasileiros e estrangeiros. As comparações com o que ocorreu na Alemanha de Hitler contemplam tópicos como agredir e ameaçar negros, índios e homossexuais, assim como na Alemanha se perseguiram judeus e ciganos.

Em relação ao segundo caso, o de Bolsonaro antiquado, houve um grande conjunto de charges que representa o presidente como um Dinossauro. O sentido mais evidente é o de reacionário, saudoso de valores que deveriam estar superados, como o machismo, a misoginia, a homofobia, a defesa das armas e a crítica a ações ambientalistas associadas a um agronegócio de feições antiquadas, além das falas grosseiras e escatológicas. Eis dois exemplos:

12 Digitando "fascismo no Brasil" verifica-se que há 6.290 .00 ocorrências. Para "Bolsonaro + nazismo", as ocorrências são 885.000. E para "Bolsonaro fascista", 1.870.000. São indícios poderosos da circulação desses discursos, mesmo que não se trate de posições unânimes. 
Figura 9 - Renato Aroeira, Humor político, 21 ago. 2018.

ERAS GEO-ILÓGICAS



Fonte: Disponível em: <https://www.humorpolitico.com.br/category/jair-bolsonaro/page/38/>

Legenda: "Eras Geo-Ilógicas"// "Tempo bom foi o Bozozóico. A terá era plana, a Bíblia era literal, todo mundo era macho e não tinha ONU..."

Figura 10 - Duke, Tribuna da Internet, 17 nov. 2017.

\section{BOLSONAURO REX}

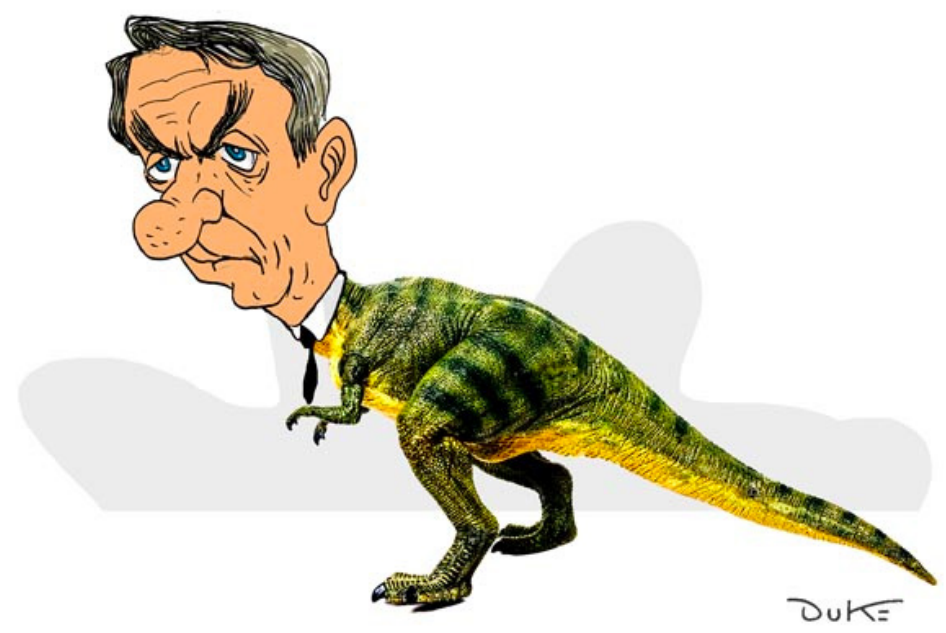

Fonte: Disponível em: <http://www.tribunadainternet.com.br/jair-bolsonaro-vem-ai-desempenhando-o-papel-doanti-lula/> 
O efeito de humor deve-se, também nestes casos, à hipérbole, visível no exagero da representação, e à metonímia, tendo em vista que, nos dois casos, o corpo de Bolsonaro remete à imagem de dinossauro. Os textos verbais escritos reforçam a associação: "Eras Geo-Ilógicas" e "Bozozóico" (Figura 9) e "Bolsonaro Rex" (Figura 10).

\section{CONSIDERAÇÕES FINAIS}

A partir da análise de um conjunto de charges, este texto buscou não apenas apresentar uma caracterização desse tipo de produção, considerando-a um gênero humorístico e opinativo, mas também examinar casos que circularam na Internet alusivos especialmente a falas e atitudes de Jair Bolsonaro (antes e depois de ele se tornar presidente), a fim de mostrar os discursos veiculados, as técnicas empregadas para produzir efeitos de humor e os ethé associados ao político. Para isso, três conceitos da Análise do Discurso foram mobilizados: memória, polêmica e ethos.

No que tange ao gênero charge, vale reforçar que, em geral, remete a pessoas conhecidas e a acontecimentos próximos de sua publicação. Trata-se de um texto breve, que consiste na retomada simplificada de cenas, fatos e pessoas. Dada essa brevidade, a recuperação ou representação integral dos elementos envolvidos nos fatos reais é impossível. Ademais, a charge pode, como tentamos mostrar:

a) retomar casos pontuais e particulares ou fatos e comportamentos constantes/recorrentes;

b) situar-se em um tempo histórico, retomando uma memória de curta ou longa duração;

c) resumir ou não uma polêmica;

d) exigir, para produzir sentido, a reconstituição dos fatos aos quais alude e que interpreta;

e) contar uma história ou referir-se a um "clima", a um "ar", sustentado ou denunciado de diversas maneiras por um discurso ou um conjunto de textos de diversos gêneros que fazem avaliação de posicionamentos. 
Em relação às falas e atitudes de Jair Bolsonaro retratadas nas charges, verificamos que elas funcionaram como uma espécie de catalisador para veicular discursos fortemente críticos que circularam e ainda circulam no Brasil, porque estão associadas à agressividade, à ignorância, à intolerância, ao autoritarismo, ao preconceito, entre outros traços. Nesse sentido, os diversos ethé associados ao presidente em questão foram: grosseiro, estúpido, violento, debochado, preconceituoso, insensato, ignorante, autoritário e antiquado.

Por fim, convém ressaltar que, como qualquer outro texto humorístico, as charges não retratam a realidade, já que não têm pretensões sociológicas nem pregam diretrizes, pois não têm função educativa ou moralizante. Contudo, não deixam de ter um papel de retratar com forte teor crítico, à sua maneira, os fatos e as pessoas, exagerando-os, caricaturando-os. Desse modo, uma das principais técnicas de produzir efeito de humor nesse gênero é o uso da hipérbole.

\section{REFERÊNCIAS}

ALMEIDA, M. R. Afinal, Jair Bolsonaro é ou não é fascista?, Folha de S.Paulo, 21 out. 2019. Disponível em: https://www1.folha.uol.com.br/ ilustrissima/2018/10/afinal-jair-bolsonaro-e-ou-nao-e-fascista.shtml. Acesso em: 5 dez. 2019.

AMOSSY, R. Apologia da polêmica. São Paulo: Contexto, 2017.

ARAÚJO, C. E. Estratégia fascista de Bolsonaro segue os mesmos passos de outros líderes autoritários, Justificando, 5 set. 2019. Disponível em: $\quad<$ http://www.justificando.com/2019/09/05/estrategia-fascista-debolsonaro-segue-os-mesmos-passos-de-outros-lideres-autoritarios/>. Acesso em: 5 dez. 2019.

BIANCHINI, L. Bolsonaro é fascista? Listamos 13 frases do candidato para reflexão, Brasil de Fato, Curitiba (PR), 17 out. 2018. Disponível em: <https://www.brasildefato.com.br/2018/10/17/bolsonaro-e-fascistalistamos-13-frases-do-candidato-para-reflexao/>. Acesso em: $5 \mathrm{dez}$. 2019.

BOLSONARO, F. Plano de governo Jair Bolsonaro, 2018. Disponível em: <http://flaviobolsonaro.com/PLANO_DE_GOVERNO_JAIR_ BOLSONARO_2018.p>. Acesso em: 5 dez. 2019.

BOURDIEU. P. Os usos sociais da ciência: por uma sociologia clínica do campo científico. Trad. D. B. Catani. São Paulo: Editora da UNESP, 2004. 
CARMELINO, A. C.; RAMOS, P. Múltiplas facetas d'O Amigo da Onça: relevância da multimodalidade na construção do ethos. In: FIGUEIREDO. M. F; FERREIRA, F. A. (Orgs.). Retórica e multimodalidade. Franca, SP: Unifran, 2018. p. 203-225.

COURTINE, J-J. Análise do discurso político. São Carlos: EdUFSCar, 2009.

DASCAL, M. Compreendendo chistes e sonhos. In: DASCAL, M. Interpretação e compreensão. São Leopoldo: Unisinos, 1999. p. 382399.

BOLSONAROfazpiada comoriental,JornalExtra, 15 mai.2019.Disponível em: $\quad<$ https://twitter.com/jornalextra/status/1128785629754667009>. Acesso em: 5 dez. 2019.

MAGALHÃES, M. Sobre lutas e lágrimas: uma bibliografia de 2018. Rio de Janeiro: Record, 2019.

MAINGUENEAU, D. Gênese dos discursos. São Paulo: Editorial Parábola, 2008.

MAINGUENEAU, D. Termos-chave da análise do discurso. Trad. M. V. Barbosa e M. E. A. T. Lima. Belo Horizonte: Editora da UFMG, 1998. MAINGUENEAU, D. O discurso literário. São Paulo: Contexto, 2005. MAINGUENEAU, D. A propósito do ethos. In: MOTA, A. R. M.; L. SALGADO, L. (Orgs.). Ethos discursivo. São Paulo: Contexto, 2008a. p. 11-29.

MAINGUENEAU, D. Problemas de ethos. In: POSSENTI, S.; SOUZAE-SILVA, M. C. P. (Orgs.). Cenas da enunciação. São Paulo, Parábola, 2008b. p. 55-73.

PAVEAU, M-Anne. Les prédiscours: sens, mémoire, cognition. Paris: Presses Sorbonne Nouvel, 2006.

PÊCHEUX, M. O papel da memória. In: ACHARD, P. et al. O papel da memória. Campinas: Pontes, 1999.

PITA, A. Bolsonaro é um dos populistas mais próximos do fascismo que já vi, El País, 4 jul. 2019, Disponível em: <https://brasil.elpais.com/ brasil/2019/06/27/cultura/1561664077_032428.html>. Acesso em: 5 dez. 2019.

POSSENTI, S. O humor é um campo. In: Cinco ensaios sobre humor e análise do discurso. São Paulo: Parábola Editorial, 2014. p. 11- 40. 
POSSENTI, S.; CARMELINO, A. C. Copa 2014 no Brasil: a logomarca virou piada. In: ARANDA. T. L; VIEIRA (Orgs.). Os sentidos do humor: possibilidades de análise do cômico. São Paulo: Verona, 2016. p. 117133.

TEIXEIRA, L. G. S. Sentidos do humor, trapaças da razão: a charge. Rio de Janeiro: Fundação Casa de Rui Barbosa, 2005.

Enviado em: 13/12/2019

Aceite em: 18/12/2019 